\title{
BMJ Open Efficaciousness of dexmedetomidine in children undergoing cleft lip and palate repair: a systematic review and meta- analysis
}

Dengfeng Liu, ${ }^{1}$ Li Pan, ${ }^{1}$ Yin Gao, ${ }^{1}$ Jiefan Liu, ${ }^{1}$ Feng Li, ${ }^{1}$ Xiangwei Li, ${ }^{2}$ Jiale Quan, ${ }^{3,4}$ Congcong Huang, ${ }^{3,4}$ Chunwei Lian (iD) ${ }^{3,4}$

To cite: Liu D, Pan L, Gao Y, et al. Efficaciousness of dexmedetomidine in children undergoing cleft lip and palate repair: a systematic review and meta-analysis. BMJ Open 2021;11:e046798. doi:10.1136/ bmjopen-2020-046798

- Prepublication history and additional supplemental material for this paper are available online. To view these files, please visit the journal online (http://dx.doi.org/10.1136/ bmjopen-2020-046798).

Received 09 November 2020 Accepted 28 July 2021

Check for updates

(C) Author(s) (or their employer(s)) 2021. Re-use permitted under CC BY-NC. No commercial re-use. See rights and permissions. Published by BMJ.

For numbered affiliations see end of article.

\section{Correspondence to}

Dr Chunwei Lian; lianchunwei0203@163.com and Dr Congcong Huang; cchuang2009@163.com

\section{ABSTRACT}

Objective To systematically assess the efficacy and safety of dexmedetomidine as an anaesthesia adjuvant for cleft lip and palate (CLP) repair in children.

Design Systematic review and meta-analysis. Data sources PubMed, Embase, Cochrane, China National Knowledge Infrastructure (CNKI), China Science and Technology Journal Database (VIP) and Wanfang (up to October 2020). Studies in languages other than English and Chinese were excluded.

Eligibility criteria for selecting studies Randomised controlled trials (RCTs) evaluating the impact of dexmedetomidine on emergence agitation (EA), the need for postoperative rescue analgesics, postoperative nausea and vomiting (PONV), and other adverse events in paediatric patients during CLP repair.

Data extraction and synthesis The quality of evidence was assessed by using the Cochrane Review Methods and the Grading of Recommendations Assessment, Development and Evaluation approach. Data were screened, extracted and assessed by two independent authors. Outcomes were reported as a risk ratio (RR) with a $95 \% \mathrm{Cl}$. A random-effect model was used when heterogeneity was detected.

Results Thirteen studies including 1040 children met the inclusion criteria. The incidence of EA was significantly decreased in the dexmedetomidine group (RR, 0.19; $95 \% \mathrm{Cl} 0.10$ to $0.36 ; p<0.00001 ; l^{2}=56 \%$ ) as compared with the control group. Paediatric patients receiving dexmedetomidine had lower postoperative analgesic requirements (RR, $0.27 ; 95 \% \mathrm{Cl} 0.10$ to $0.73 ; \mathrm{p}=0.01$; $\left.\mathrm{I}^{2}=84 \%\right)$ and a lower incidence of respiratory adverse events (RR, $0.49 ; 95 \% \mathrm{Cl} 0.31$ to $0.78 ; \mathrm{p}=0.003 ; \mathrm{l}^{2}=0 \%$ ). There were no significant differences in the risk of PONV and cardiovascular adverse events.

Conclusions There was a lack of high-quality studies in this field. Perioperative administration of dexmedetomidine reduced the need for postoperative rescue analgesics and the incidence of EA in children without side effects undergoing CLP repair. However, further verification with larger samples and higher-quality RCTs is needed.

\section{INTRODUCTION}

Cleft lip and palate (CLP) are widespread congenital disfigurements requiring surgical
Strengths and limitations of this study

- Studies in both English language and Chinese language were included.

- This is a comprehensive systematic review that identified the benefits of dexmedetomidine in children undergoing cleft lip and palate repair.

- Heterogeneity was observed in the doses, the timing of administration and evaluation methods for the outcomes across studies.

- For some comparisons, the numbers of trials included and the outcomes reported were small.

- The low quality of the included studies impedes us from drawing firm conclusions.

correction early in life. ${ }^{1}$ Early surgery is important to alleviate feeding difficulty, reduce airway complications and improve phonation problems. ${ }^{2}$ However, cleft palate repair is needed to dissect the soft and hard palates and may result in significant postoperative oropharyngeal pain and bleeding. High-dose opioids with sevoflurane anaesthesia are commonly used to block the autonomic response, ${ }^{3}$ while many paediatric patients suffer from high risks of respiratory depression, postoperative emergence agitation (EA), postoperative nausea and vomiting (PONV), prolonged hospital stay and increased hospital costs. ${ }^{4-6}$

Dexmedetomidine is a potent $\alpha 2$-adrenoreceptor agonist with sedative, anxiolytic, sympatholytic and analgesic properties. It alleviated the autonomic response to surgery and ensured a stable haemodynamic state without significant respiratory depression. ${ }^{7}$ One previous study ${ }^{8}$ had demonstrated that dexmedetomidine was helpful as a valuable adjunct for multiple applications and was increasingly used in paediatric anaesthesia settings. A meta-analysis ${ }^{9}$ recently showed that perioperative administration of 
dexmedetomidine can provide pain and agitation relief without side effects in children undergoing adenotonsillectomy. Another meta-analysis ${ }^{10}$ found that intranasal dexmedetomidine provided more satisfactory sedation at parent separation and reduced the need for postoperative rescue analgesics in paediatric patients. However, evidences in the existing literature were still insufficient to fully support the effective and safe use of dexmedetomidine in children undergoing CLP repair.

Therefore, our study aimed to identify the efficacy and safety of dexmedetomidine in children during CLP repair. We performed a meta-analysis of randomised controlled trials (RCTs) comparing dexmedetomidine with controls.

\section{METHODS}

We evaluated the efficacy and safety of dexmedetomidine administration during CLP repair in children. A systematic review approach based on the Preferred Reporting Items for Systematic Reviews and Meta-Analyses and the Cochrane Review Method was used. ${ }^{11}$

\section{Search strategy and selection criteria}

We searched the following databases from inception to 1 October 2020: PubMed, Embase, Cochrane Library, China National Knowledge Infrastructure (CNKI), China Science and Technology Journal Database (VIP) and Wanfang. The main keywords used were the following: dexmedetomidine, RCT, cleft palate, cleft lip, infant and children. The reference lists of identified studies were searched for additional eligible studies (search strategy of PubMed as online supplemental file 1).

\section{Inclusion and exclusion criteria}

Two authors (LP and YG) systematically and independently identified all the studies using predefined selection criteria. A third author (XL) resolved disagreements when conflicting selections occurred. Studies were included in this meta-analysis if they met the following criteria: (1) literature type: prospective, randomised controlled studies; (2) language: both English and Chinese; (3) subjects: children undergoing CLP repair; (4) interventions: dexmedetomidine by any route of administration compared with any controls (including saline and other drugs); and (5) outcomes: the primary outcome was the incidence of EA, the secondary outcome was the need for postoperative rescue analgesia and the third outcomes were the incidence of adverse effects: PONV, respiratory adverse effects (breath-holding, cough, desaturation and airway spasm) and cardiovascular adverse effects (hypotension, bradycardia and postoperative bleeding).

\section{Data collection}

Two authors (JL and FL) independently extracted all the relevant information with a prespecified data abstraction form. The following variables were collected: the name of the first author, publication year, country, publication language, other anaesthetic agents, number of patients, protocol for administration method and dose and outcomes. If the variables were not reported, we emailed the original authors to ask for the data.

\section{Risk of bias across studies}

Two authors (JL and FL) independently assessed the risk of bias based on the Cochrane risk of bias tool, which considers the following aspects: adequate sequence generation, allocation concealment, blinding of participants and personnel, blinding of the outcome assessor, incomplete reporting of outcome data, free of selective reporting and free of other bias. We assessed the risk of bias based on the information presented in the studies, with no assumptions: low risk of bias, high risk of bias or unclear risk of bias. In case of conflicting evaluations, a third author (XL) was consulted to resolve disagreements.

\section{Quality of the evidence}

The quality of evidence was assessed using the Grading of Recommendations Assessment, Development and Evaluation approach (GRADE). We used GRADE profiler software V.3.2 to create the 'Summary of findings' table, which includes the following outcomes: (1) EA, (2) respiratory adverse events, (3) the need for postoperative rescue analgesics, (4) cardiovascular adverse events and (5) PONV.

\section{Publication bias across studies}

Publication bias was assessed by using a funnel plot or Begg's test.

\section{Statistical analysis}

The meta-analysis was performed using Cochrane Collaboration Review Manager Software (RevMan V.5.1, https:/ / training.cochrane.org/). We reported binary data as a risk ratio (RR) with a $95 \%$ CI. The $\mathrm{X}^{2}$ test (Mantel-Haenszel method) was used to assess the heterogeneity between studies. An $\mathrm{I}^{2}>50 \%$ and a $\mathrm{p}$ value $<0.10$ were considered to indicate statistical heterogeneity. Subgroup analysis or sensitivity analysis was performed to analyse reasons for heterogeneity. A random-effect model (DerSimonian and Laird method) was used when significant statistical or clinical heterogeneity was detected. $\mathrm{P} \leq 0.05$ was considered to indicate a statistically significant difference for testing values of the overall effect.

\section{Patient and public involvement}

There was no patient or public involvement in this study.

\section{RESULTS}

\section{Study selection}

A total of 63 potentially relevant studies were identified. After excluding 50 studies, 13 studies including 1040 children aged 3 months to 12 years were finally included in this analysis. ${ }^{12-24}$ The flow diagram of the literature search strategy is shown in figure 1. 


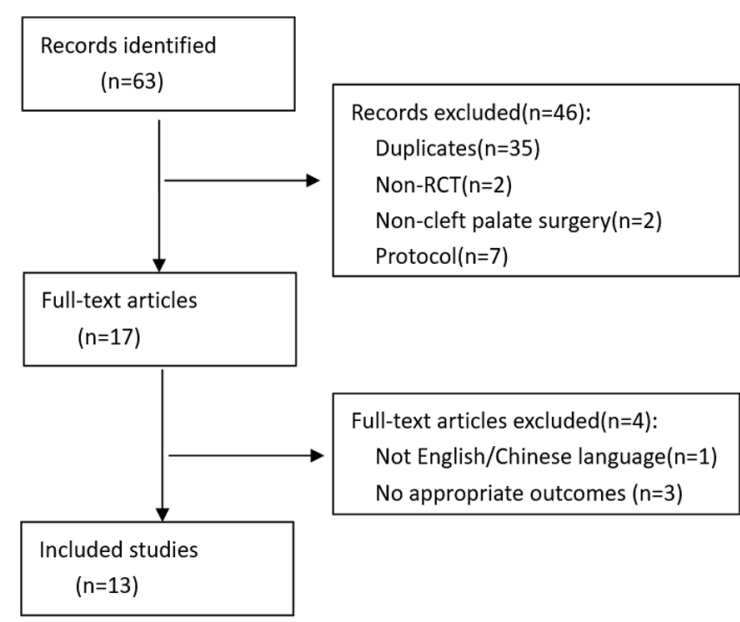

Figure 1 Flow diagram of the literature search strategy. $\mathrm{RCT}$, randomised controlled trials.

\section{Description of studies}

The included studies were undertaken from 2012 to 2020 in four different countries: Egypt (three),${ }^{12-14}$ Japan (one), ${ }^{16}$ India (one) $)^{17}$ and China (eight). ${ }^{15}$ 18-24 Seven studies $^{12-18}$ were published in English, and the other six studies ${ }^{19-24}$ were published in Chinese. In all of the included studies, dexmedetomidine was administered via intravenous, ${ }^{1521} 2324$ intranasal $^{22}$ and perineural ${ }^{12-14}$ administration.

Eleven studies ${ }^{12}$ 14-19 21-24 compared the effects of intravenous dexmedetomidine with saline, and one study ${ }^{20}$ compared the effects of intravenous dexmedetomidine with those of ketamine and fentanyl. One study ${ }^{22}$ compared the effects of intranasal dexmedetomidine with saline. Two studies ${ }^{12} 14$ compared the effects of perineural dexmedetomidine administration with saline, and one study ${ }^{13}$ compared the effects of perineural dexmedetomidine administration with those of dexamethasone. The characteristics of the included studies are summarised in table 1 .

\section{Risk of bias across studies}

The risk of bias of included studies can be found in table 2, figure 2 and online supplemental file 2. Nine studies $^{12} 1315-192224$ used a random allocation method. Four studies ${ }^{13-15} 17$ described the allocation concealment in detail. Four studies ${ }^{12}{ }^{16-18}$ concretely explained their blinding methods. The risk of the random allocation method was high in one study ${ }^{20}$ and was unclear in the other three studies. ${ }^{142123}$ The risk of allocation concealment was unclear, and the risk of blinding was high in the other studies. The risk of free of selective reporting was low in eight studies, ${ }^{12} 14$ 17-20 $22{ }^{23}$ unclear in one study ${ }^{16}$ and high in other studies. For incomplete outcome data and free of other bias, most trials were judged as having a low risk of bias. The quality of the included trials is summarised in table 2, figure 2 and online supplemental file 2.

\section{Quality of the included studies}

The overall quality of evidence based on the GRADE system was judged as moderate (the need for postoperative rescue analgesics, respiratory adverse events and cardiovascular adverse events) or low (EA and PONV) (table 3).

\section{Publication bias across studies}

Test for funnel plot asymmetry was inappropriate to assess risk of publication bias. Since no significant asymmetry patterns were identified in Begg's test (online supplemental file 3), we concluded no significant publication bias. Due to the small number of studies, the power is still low.

\section{Emergence agitation}

Eight trials ${ }^{15} 18-24$ including 684 patients reported the incidence of EA. EA was evaluated by the Ramsay Score, Behaviour Score, Paediatric Anaesthesia Emergence Delirium Scale or Aono's Four-Point Scale. Dexmedetomidine administration (including intravenous and intranasal administration) showed significant evidence of reduced EA when compared with saline ${ }^{15} 1819$ 21-24 (RR, $0.19 ; 95 \%$ CI 0.10 to $0.38 ; \mathrm{p}<0.00001 ; \mathrm{I}^{2}=62 \%$ ) and all control groups ${ }^{15}{ }^{18-24}$ (RR, $0.19 ; 95 \%$ CI 0.10 to 0.36 ; $\left.\mathrm{p}<0.00001 ; \mathrm{I}^{2}=56 \%\right)$. We found that different administration methods of dexmedetomidine increased the clinical heterogeneity. Excluding the 2016 study by Yun ${ }^{22}$ (intranasal administration), intravenous dexmedetomidine administration showed a significant evidence of reduced EA when compared with saline $e^{15} 1819212324$ (RR, $0.24 ; 95 \%$ CI 0.13 to $0.44 ; \mathrm{p}<0.00001 ; \mathrm{I}^{2}=40 \%$ ) and when compared with all control groups ${ }^{15} 18-212324$ (RR, $0.24 ; 95 \%$ CI 0.14 to $0.41 ; \mathrm{p}<0.00001 ; \mathrm{I}^{2}=29 \%$ ). However, subgroup analysis showed no difference when dexmedetomidine was compared with intravenous fentanyl ${ }^{20}$ (RR, $0.14 ; 95 \%$ CI 0.01 to $2.58 ; \mathrm{p}=0.19$ ) and intravenous ketamine $\mathrm{e}^{20}$ (RR, $0.14 ; 95 \%$ CI 0.01 to 2.58 ; $\mathrm{p}=0.19$ ) (figure 3).

\section{The need for postoperative rescue analgesics}

Five studies ${ }^{12} 14171823$ including 293 paediatric patients reported that dexmedetomidine had a greater analgesic effect than saline postoperatively (RR, 0.27 ; 95\% CI 0.10 to $\left.0.73 ; \mathrm{p}=0.01 ; \mathrm{I}^{2}=84 \%\right)$. In contrast to the two studies that used perineural administration, ${ }^{12}{ }^{14}$ intravenous dexmedetomidine administration ${ }^{171823}$ showed a significant analgesic effect when compared with saline (RR, $0.26 ; 95 \%$ CI 0.16 to $0.44 ; \mathrm{p}<0.00001 ; \mathrm{I}^{2}=0 \%$ ). Subgroup analysis showed that there was no difference when perineural dexmedetomidine ${ }^{1214}$ was compared with saline in the incidence of need for rescue analgesics at postoperative 24 hours (RR, 0.16 ; $95 \%$ CI 0.00 to 33.36 ; $\mathrm{p}=0.50$ ).

\section{Respiratory adverse events}

Eight studies ${ }^{15-21} 23$ including 794 paediatric patients reported the number of respiratory adverse events. We found that intravenous dexmedetomidine administration showed a significantly lower incidence of respiratory 


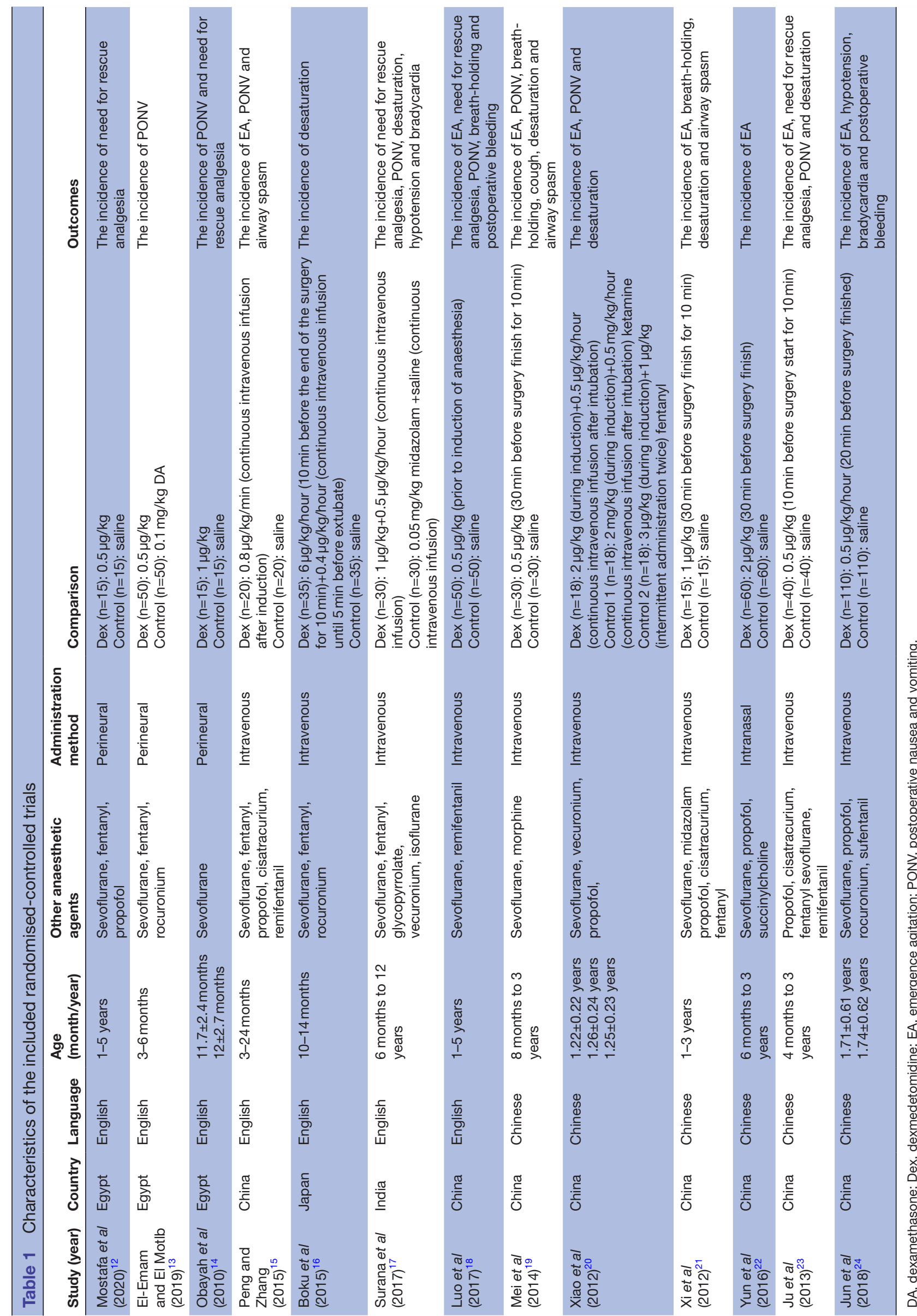


Table 2 Individual randomised controlled trial methodological quality

\begin{tabular}{|c|c|c|c|c|c|c|c|}
\hline Study (year) & $\begin{array}{l}\text { Adequate } \\
\text { sequence } \\
\text { generation }\end{array}$ & $\begin{array}{l}\text { Allocation } \\
\text { concealment }\end{array}$ & $\begin{array}{l}\text { Blinding of } \\
\text { participants } \\
\text { and personnel }\end{array}$ & $\begin{array}{l}\text { Blinding of } \\
\text { outcome } \\
\text { assessment }\end{array}$ & $\begin{array}{l}\text { Incomplete } \\
\text { outcome data } \\
\text { addressed }\end{array}$ & $\begin{array}{l}\text { Free of } \\
\text { selective } \\
\text { reporting }\end{array}$ & $\begin{array}{l}\text { Free of } \\
\text { other } \\
\text { bias }\end{array}$ \\
\hline Mostafa et al (2020) $)^{12}$ & Yes & $?$ & Yes & Yes & Yes & Yes & Yes \\
\hline $\begin{array}{l}\text { El-Emam and El Motlb } \\
(2019)^{13}\end{array}$ & Yes & Yes & No & Yes & Yes & No & Yes \\
\hline Obayah et al (2010) & $?$ & Yes & No & No & Yes & Yes & Yes \\
\hline Boku et al (2015) & Yes & $?$ & Yes & Yes & Yes & $?$ & Yes \\
\hline Surana et al (2017) $)^{17}$ & Yes & Yes & Yes & Yes & Yes & Yes & Yes \\
\hline Luo et al $(2017)^{18}$ & Yes & $?$ & Yes & Yes & Yes & Yes & No \\
\hline Mei et al $(2014)^{19}$ & Yes & $?$ & No & No & Yes & Yes & Yes \\
\hline Ju et al (2013) ${ }^{23}$ & $?$ & $?$ & No & No & Yes & Yes & Yes \\
\hline Jun et al (2018) & Yes & $?$ & No & No & Yes & No & Yes \\
\hline
\end{tabular}

?, unclear risk of bias; No, high risk of bias; Yes, low risk of bias.

adverse events than saline administration (RR, 0.49; $95 \%$ CI 0.31 to $\left.0.78 ; \mathrm{p}=0.003 ; \mathrm{I}^{2}=0 \%\right)$. Only one study ${ }^{19}$ $(\mathrm{n}=60)$ reported that dexmedetomidine showed a significantly lower incidence of cough than saline (RR, 0.45; $95 \%$ CI 0.25 to $0.82 ; p=0.009$ ). There were no differences when dexmedetomidine was compared with saline in the incidence of breath-holding ${ }^{181921}$ (RR, $1.35 ; 95 \%$ CI 0.31 to $\left.5.92 ; \mathrm{p}=0.69 ; \mathrm{I}^{2}=0 \%\right)$, desaturation ${ }^{161719-21} 23$ (RR, 0.47; $95 \%$ CI 0.17 to $\left.1.29 ; \mathrm{p}=0.14 ; \mathrm{I}^{2}=0 \%\right)$ or airway $\operatorname{spasm}^{15} 1921$ (RR, $0.33 ; 95 \%$ CI 0.07 to $1.54 ; \mathrm{p}=0.16 ; \mathrm{I}^{2}=0 \%$ ).

Cardiovascular adverse events

Three studies ${ }^{171824}$ including 880 paediatric patients reported the number of cardiovascular adverse events. We found no differences when dexmedetomidine was compared with saline in the incidence of hypotension ${ }^{17} 24$ (RR, $1.18 ; 95 \%$ CI 0.61 to 2.28; $\mathrm{p}=0.62$ ), bradycardia ${ }^{17} 24$ (RR, $0.78 ; 95 \%$ CI 0.30 to $2.07 ; \mathrm{p}=0.62$ ) or postoperative bleeding $^{18}{ }^{24}$ (RR, $0.45 ; 95 \%$ CI 0.17 to $1.15 ; \mathrm{p}=0.09$; $\mathrm{I}^{2}=0 \%$ ).

\section{Postoperative nausea and vomiting}

Eight trials ${ }^{13-1517-2023}$ including 524 patients reported the incidence of PONV. Patients who received dexmedetomidine administration experienced no statistically significant increase in PONV when compared with saline ${ }^{1415}$ 17-1923 (RR, 0.95 ; 95\% CI 0.41 to $2.19 ; \mathrm{p}=0.91 ; \mathrm{I}^{2}=0 \%$ ) and when compared with all control groups ${ }^{13-15}$ 17-20 23 (RR, 0.96; $95 \%$ CI 0.48 to $1.90 ; \mathrm{p}=0.90 ; \mathrm{I}^{2}=0 \%$ ). Subgroup analysis showed that there was also no difference when perineural
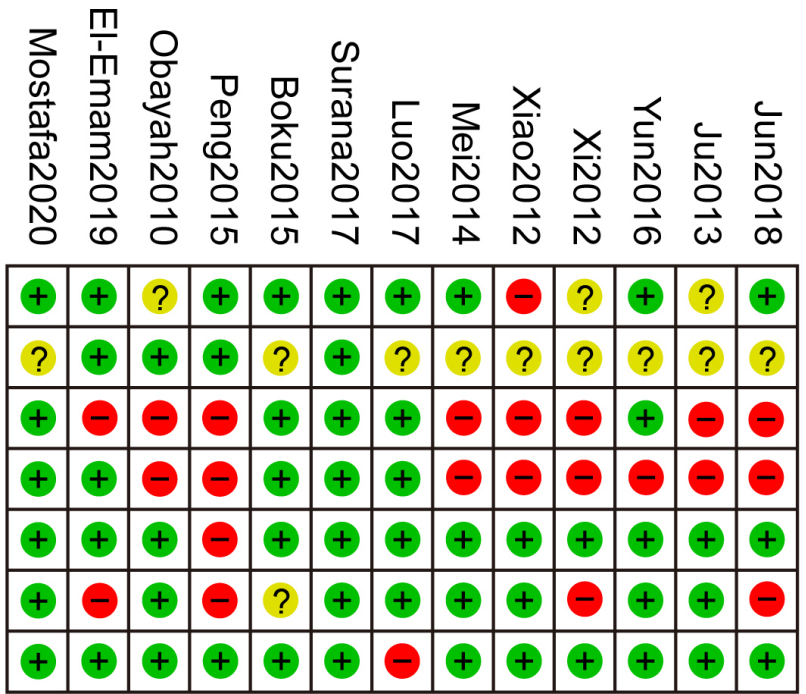

+ low risk of bias

$\vartheta$ high risk of bias

? unclear risk of bias

Adequate sequence generation (selection bias)

Allocation concealment (selection bias)

Blinding of Participants and Personnel (performance bias)

Blinding of Outcome Assessment (detection bias)

Incomplete outcome data addressed (attrition bias)

Free of selective reporting (reporting bias)

Free of other bias (other bias)

Figure 2 Risk of bias of the included studies. 
Table 3 Summary of findings for the main outcomes

\section{Dexmedetomidine for cleft lip and palate repair}

Patient or population: patients with cleft lip and palate repair

Settings: surgery

Intervention: dexmedetomidine

\begin{tabular}{|c|c|c|c|c|c|c|}
\hline \multirow[b]{3}{*}{ Outcomes } & \multicolumn{2}{|c|}{$\begin{array}{l}\text { Illustrative comparative risks* } \\
(95 \% \mathrm{Cl})\end{array}$} & \multirow{3}{*}{$\begin{array}{l}\text { Relative effect } \\
(95 \% \mathrm{Cl})\end{array}$} & \multirow{3}{*}{$\begin{array}{l}\text { No of } \\
\text { participants } \\
\text { (studies) }\end{array}$} & \multirow{3}{*}{$\begin{array}{l}\text { Quality of } \\
\text { the evidence } \\
\text { (GRADE) }\end{array}$} & \multirow[b]{3}{*}{ Comments } \\
\hline & $\begin{array}{l}\text { Assumed } \\
\text { risk }\end{array}$ & Corresponding risk & & & & \\
\hline & Control & Dexmedetomidine & & & & \\
\hline \multirow[t]{2}{*}{ Emergence agitation } & \multicolumn{2}{|c|}{ Study population } & \multirow{2}{*}{$\begin{array}{l}\text { RR } 0.19(0.10 \text { to } \\
0.36)\end{array}$} & \multirow{2}{*}{$\begin{array}{l}684 \text { (eight } \\
\text { studies) }\end{array}$} & \multirow{2}{*}{ 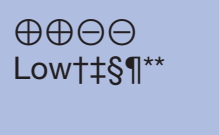 } & \\
\hline & $\begin{array}{l}458 \text { per } \\
1000\end{array}$ & 87 per 1000 (46 to 165$)$ & & & & \\
\hline \multirow{2}{*}{$\begin{array}{l}\text { Respiratory adverse } \\
\text { events }\end{array}$} & \multicolumn{2}{|c|}{ Study population } & \multirow{2}{*}{$\begin{array}{l}\text { RR } 0.49 \text { (0.31 to } \\
0.78)\end{array}$} & \multirow{2}{*}{$\begin{array}{l}794 \text { (eight } \\
\text { studies) }\end{array}$} & \multirow{2}{*}{$\begin{array}{l}\oplus \oplus \oplus \ominus \\
\text { Moderate††† }\end{array}$} & \\
\hline & $\begin{array}{l}103 \text { per } \\
1000\end{array}$ & 50 per 1000 (32 to 80$)$ & & & & \\
\hline \multirow{2}{*}{$\begin{array}{l}\text { The need for } \\
\text { postoperative } \\
\text { rescue analgesics }\end{array}$} & \multicolumn{2}{|c|}{ Study population } & \multirow{2}{*}{$\begin{array}{l}\text { RR } 0.27 \text { (0.1 to } \\
0.73)\end{array}$} & \multirow[t]{2}{*}{293 (five studies) } & \multirow{2}{*}{$\begin{array}{l}\oplus \oplus \oplus \ominus \\
\text { Moderate†‡†† }\end{array}$} & \\
\hline & $\begin{array}{l}592 \text { per } \\
1000\end{array}$ & 160 per 1000 (59 to 432$)$ & & & & \\
\hline \multirow{2}{*}{$\begin{array}{l}\text { Cardiovascular } \\
\text { adverse events }\end{array}$} & \multicolumn{2}{|c|}{ Study population } & \multirow{2}{*}{$\begin{array}{l}\text { RR } 0.83 \text { (0.52 to } \\
1.31)\end{array}$} & \multirow{2}{*}{$\begin{array}{l}880 \text { (three } \\
\text { studies) }\end{array}$} & \multirow{2}{*}{$\begin{array}{l}\oplus \oplus \oplus \ominus \\
\text { Moderate }\end{array}$} & \\
\hline & $\begin{array}{l}105 \text { per } \\
1000\end{array}$ & 87 per 1000 (55 to 138$)$ & & & & \\
\hline \multirow{2}{*}{$\begin{array}{l}\text { Postoperative } \\
\text { nausea and } \\
\text { vomiting }\end{array}$} & \multicolumn{2}{|c|}{ Study population } & \multirow{2}{*}{$\begin{array}{l}\text { RR } 0.92(0.47 \text { to } \\
1.80)\end{array}$} & \multirow{2}{*}{$\begin{array}{l}524 \text { (eight } \\
\text { studies) }\end{array}$} & \multirow[t]{2}{*}{$\oplus \oplus \ominus \ominus$ Low $\dagger$} & \\
\hline & $\begin{array}{l}63 \text { per } \\
1000\end{array}$ & 58 per 1000 (30 to 113 ) & & & & \\
\hline
\end{tabular}

GRADE Working Group grades of evidence.

High quality: further research is very unlikely to change our confidence in the estimate of effect.

Moderate quality: further research is likely to have an important impact on our confidence in the estimate of effect and may change the estimate.

Low quality: further research is very likely to have an important impact on our confidence in the estimate of effect and is likely to change the estimate.

Very low quality: we are very uncertain about the estimate.

${ }^{*}$ The basis for the assumed risk (eg, the median control group risk across studies) is provided in footnotes. The corresponding risk (and its $95 \% \mathrm{Cl}$ ) is based on the assumed risk in the comparison group and the relative effect of the intervention (and its $95 \% \mathrm{Cl}$ ).

†Allocation concealment and/or blinding of outcome assessors unclear/inadequate in $50 \%$ or more of the included studies.

$\ddagger$ Significant heterogeneity $\left(1^{2}>50 \%\right)$ is partially explained by different administration method, dose and comparators.

$\S$ Use of several different scoring criteria to evaluate emergence agitation.

१A dose-response gradient was present.

${ }^{*} \mathrm{RR}>5$ or $<0.2$.

t†RR $>2$ or $<0.5$.

GRADE, Grading of Recommendations Assessment, Development and Evaluation; RR, risk ratio.

dexmedetomidine was compared with control groups. ${ }^{13} 14$ Additionally, another subgroup analysis showed no difference when intravenous dexmedetomidine was compared with fentanyl ${ }^{20}$ (RR, $0.50 ; 95 \%$ CI 0.06 to 4.15 ; $\mathrm{p}=0.52$ ) and ketamine $^{20}$ (RR, 0.50 ; 95\% CI 0.06 to 4.15 ; $\mathrm{p}=0.52$ ) or when perineural dexmedetomidine was compared with dexamethasone $^{13}$ (RR, 1.33; $95 \%$ CI 0.31 to 5.65 ; $\left.\mathrm{p}=0.70\right)$.

\section{DISCUSSION}

\section{Main findings}

This meta-analysis revealed that perioperative administration of dexmedetomidine reduced the incidence of EA in children undergoing CLP repair. Paediatric patients receiving dexmedetomidine had a lower need for rescue analgesics postoperatively and a lower incidence of respiratory adverse events. However, there were no significant differences in the risk of PONV and cardiovascular adverse events.

Although dexmedetomidine is not approved by the US Food and Drug Administration for administration in children, it has been an authorised drug in Europe since September $2011 .^{25}$ It is increasingly used in the paediatric setting for various indications such as premedication, adjunct, sedative, intraoperative analgesia and adjuvant therapy, ${ }^{8}$ but the efficacy is still controversial.

Our results found that both the incidence of EA and the need for rescue analgesics postoperatively were significantly decreased in the dexmedetomidine group as 


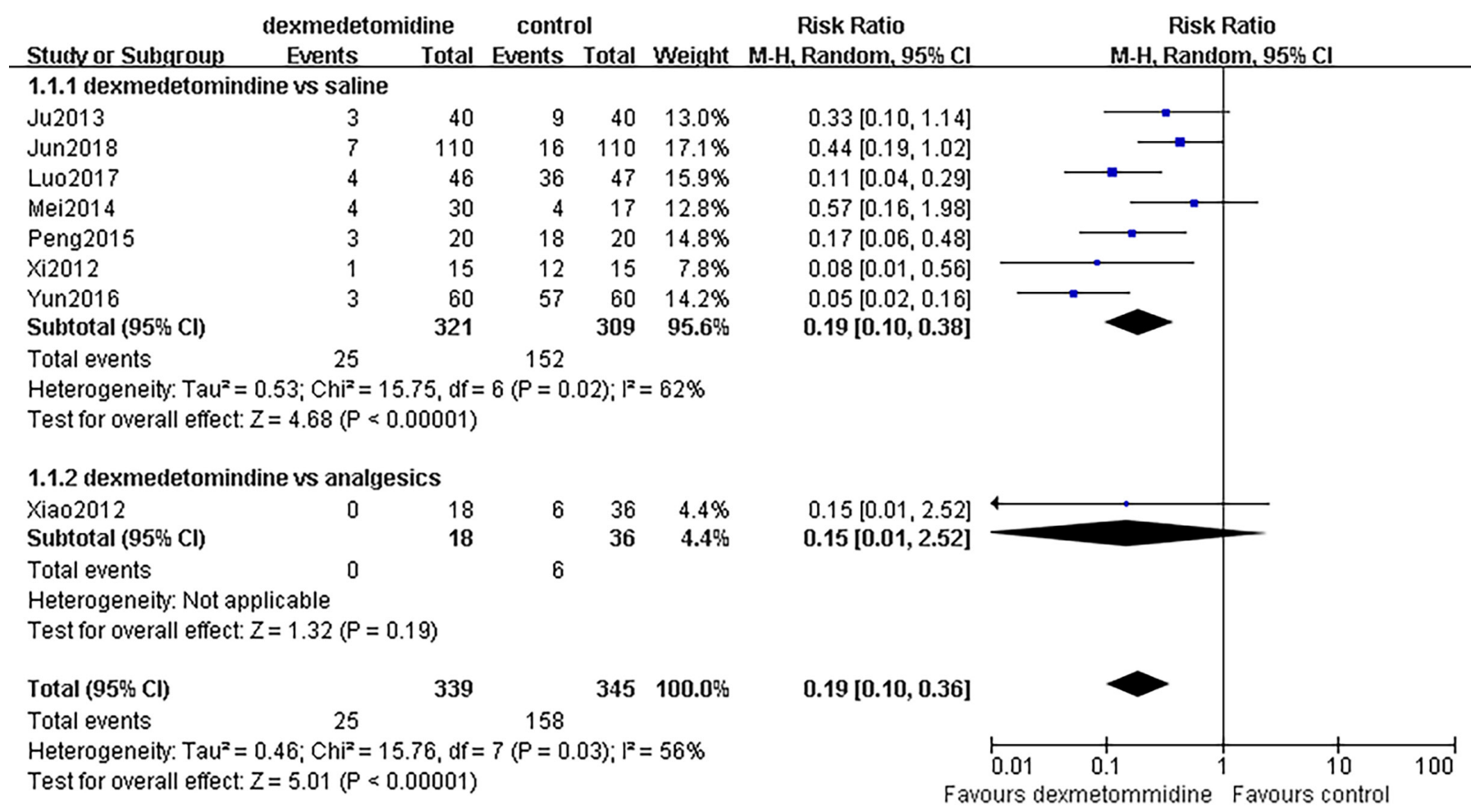

Figure 3 Perioperative dexmedetomidine versus control groups for emergence agitation.

compared with the saline group. This was consistent with previous studies. ${ }^{46910}$ Two recent meta-analyses ${ }^{2627}$ found that the effects of dexmedetomidine on reducing the risk of EA in children were superior to those of other drugs (including fentanyl, propofol and ketamine), which was inconsistent with our study. Numerous aetiological factors (such as pre-existing anxiety, pain, age, type of surgical procedures, rapid awakening and anaesthetic technique) were considered to cause EA. ${ }^{28}$ All of the included studies used sevoflurane anaesthesia. It is widely believed that pain relief decreases the incidence of EA associated with sevoflurane general anaesthesia. ${ }^{28}$ Dexmedetomidine shows dose-dependent effects on pain control and sedation. Reliable analgesic, sedative and neuroprotective effects could be the main explanations for the effects of dexmedetomidine on EA.

Respiration is slightly affected by dexmedetomidine. ${ }^{7-9}$ Our meta-analysis showed that dexmedetomidine did not influence the incidence of breath-holding, desaturation or airway spasm. In contrast, the incidence of cough and total respiratory adverse events were decreased in the dexmedetomidine group. This was attributed to the residual sedation caused by the sedative effect of dexmedetomidine. Due to the rapid decrease in the concentration of sevoflurane during the recovery period, rapidly awakening paediatric patients were in a highly sensitive state. It has minimal respiratory changes from the residual sedation, even extubation during the infusion of dexmedetomidine, in contrast to other sedatives. ${ }^{7}$ However, we should pay attention to the fact that the strength of residual sedation was related to the early phase of postanaesthesia recovery time in postoperative anaesthesia care unit.

As a selective $\alpha 2$-agonist, dexmedetomidine acts on the autonomic ganglia and exerts its cardiovascular effect by decreasing sympathetic outflow and augmenting vagal activity; thus, low infusion rates could cause bradycardia and hypotension, while high doses could cause hypertension and aggravate bradycardia. ${ }^{78}$ In addition to the dose, rapid injection may result in excessive haemodynamic alterations, and it is recommended that dexmedetomidine be administered slowly. Only two of thirteen included studies reported the incidence of bradycardia and hypotension. One study administered dexmedetomidine as a loading dose over $10 \mathrm{~min}$ and followed by a maintenance infusion of $0.5 \mu \mathrm{g} / \mathrm{kg} /$ hour until the last suture was applied, while the other study administrated dexmedetomidine as a maintenance infusion of $0.5 \mu \mathrm{g} /$ $\mathrm{kg} /$ hour intravenously after the induction of anaesthesia until $20 \mathrm{~min}$ before the surgery was finished. There was no significant difference in the dexmedetomidine group as compared with the placebo group. The haemodynamic stability was due to the method of low dose, slow injection and continuous infusion.

Few studies have focused on the effect of dexmedetomidine on PONV. Dexmedetomidine did not affect the incidence of PONV in our meta-analysis. This was consistent with a recent systematic review ${ }^{29}$ in which dexmedetomidine intraoperative administration had no effect PONV during paediatric surgery, but it was inconsistent with a recent systematic review ${ }^{30}$ in which dexmedetomidine was superior to placebo with a reduction in the need 
for an antiemetic in adults undergoing gynaecological surgery. Another study also showed that dexmedetomidine appeared to prevent postoperative vomiting after sevoflurane anaesthesia for paediatric strabismus surgery. In their opinion, it is difficult to estimate the true incidence of nausea in younger children. ${ }^{31}$ This may be the explanation for the different effects of dexmedetomidine on PONV between children and adults.

\section{Limitations}

There were some limitations in methodology. First, most of the studies were focused on developing countries, which might be relevant because CLP disease was common in developing countries. But only one study was designed with a low risk of bias, and the others had a moderate risk of bias. There are some possibilities of selective bias, detection bias, performance bias and so on. Second, due to differences in the doses and timing of administration, we did not use subgroup analysis for the administration doses. To a certain extent, it affected the strength of the system review.

\section{CONCLUSIONS}

Our findings demonstrate that perioperative administration of dexmedetomidine in children undergoing CLP repair efficiently decreases pain, EA and respiratory adverse events. However, standardised usage and dosage need further investigation, and larger rigorous studies need to be included.

\section{Author affiliations}

${ }^{1}$ Department of Oral Maxillofacial Surgery, School and Hospital of Stomatology, Wenzhou Medical University, Wenzhou, Zhejiang, China

${ }^{2}$ Department of Rehabilitation, Air Force Health Care Center For Special Service Hangzhou, Hangzhou, Zhejiang, China

${ }^{3}$ Department of Anesthesiology and Perioperative Medicine, The Second Affiliated Hospital and Yuying Children's Hospital of Wenzhou Medical University, Wenzhou, Zhejiang, China

${ }^{4}$ Key Laboratory of Anesthesiology of Zhejiang Province, Wenzhou Medical University, Wenzhou, Zhejiang, China

Contributors LP, YG and XL helped read and screen abstracts and titles of potentially relevant studies. JL, FL and XL helped read the retained papers and were responsible for extracting data and assessing their quality independently. DL helped design the study, conduct the study, analyse the data and write the manuscript. JQ helped revise the paper with language. $\mathrm{CH}$ and $\mathrm{CL}$ helped design the study, conduct the study, analyse the data and revise the manuscript. All authors contributed to conceptualise ideas, interpret findings and reviewed drafts of the manuscript.

Funding This work was supported by Wenzhou Public Welfare Science and Technology Program grant number Y2020592.

Competing interests None declared.

Patient consent for publication Not required.

Ethics approval Ethics approval to collect the patients' data was not required by the ethics committee of the Second Affiliated Hospital of Wenzhou Medical University.

Provenance and peer review Not commissioned; externally peer reviewed.

Data availability statement All data relevant to the study are included in the article or uploaded as supplemental information.

Supplemental material This content has been supplied by the author(s). It has not been vetted by BMJ Publishing Group Limited (BMJ) and may not have been peer-reviewed. Any opinions or recommendations discussed are solely those of the author(s) and are not endorsed by BMJ. BMJ disclaims all liability and responsibility arising from any reliance placed on the content. Where the content includes any translated material, BMJ does not warrant the accuracy and reliability of the translations (including but not limited to local regulations, clinical guidelines, terminology, drug names and drug dosages), and is not responsible for any error and/or omissions arising from translation and adaptation or otherwise.

Open access This is an open access article distributed in accordance with the Creative Commons Attribution Non Commercial (CC BY-NC 4.0) license, which permits others to distribute, remix, adapt, build upon this work non-commercially, and license their derivative works on different terms, provided the original work is properly cited, appropriate credit is given, any changes made indicated, and the use is non-commercial. See: http://creativecommons.org/licenses/by-nc/4.0/.

ORCID iD

Chunwei Lian http://orcid.org/0000-0003-4702-6147

\section{REFERENCES}

1 Somerville N, Fenlon S. Anaesthesia for cleft lip and palate surgery. Contin Educ Anaesth Crit Care Pain 2005;5:76-9.

2 Takemura H, Yasumoto K, Toi T, et al. Correlation of cleft type with incidence of perioperative respiratory complications in infants with cleft lip and palate. Paediatr Anaesth 2002;12:585-8.

3 Tremlett M. Anaesthesia for cleft lip and palate surgery. Curr Anaesth Crit Care 2004;15:309-16.

4 Dahmani S, Stany I, Brasher C, et al. Pharmacological prevention of sevoflurane- and desflurane-related emergence agitation in children: a meta-analysis of published studies. Br J Anaesth 2010;104:216-23.

5 Nguyen C, Hernandez-Boussard T, Davies SM, et al. Cleft palate surgery: an evaluation of length of stay, complications, and costs by hospital type. Cleft Palate Craniofac J 2014;51:412-9.

6 Lin T-F, Yeh Y-C, Lin F-S, et al. Effect of combining dexmedetomidine and morphine for intravenous patient-controlled analgesia. Br J Anaesth 2009;102:117-22.

7 Su F, Hammer GB. Dexmedetomidine: pediatric pharmacology, clinical uses and safety. Expert Opin Drug Saf 2011;10:55-66.

8 Sottas CE, Anderson BJ. Dexmedetomidine: the new all-in-one drug in paediatric anaesthesia? Curr Opin Anaesthesiol 2017;30:441.

9 Cho HK, Yoon HY, Jin HJ, et al. Efficacy of dexmedetomidine for perioperative morbidities in pediatric tonsillectomy: a metaanalysis. Laryngoscope 2018;128:E184-93.

10 Jun JH, Kim KN, Kim JY, et al. The effects of intranasal dexmedetomidine premedication in children: a systematic review and meta-analysis. Can J Anaesth 2017;64:947-61.

11 Higgins JPT, Green S, eds. Cochrane handbook for systematic reviews of interventions. Version 5.1.0 (updated march 2016). The Cochrane Collaboration, 2016. http://handbook.cochrane.org/

12 Mostafa MF, Aal FAA, Ali IH, et al. Dexmedetomidine during suprazygomatic maxillary nerve block for pediatric cleft palate repair, randomized double-blind controlled study. Korean J Pain 2020;33:81-9.

13 El-Emam E-SM, El Motlb EAA. Comparative evaluation of dexamethasone and dexmedetomidine as adjuvants for bupivacaine in ultrasound-guided infraorbital nerve block for cleft lip repair: a prospective, randomized, double-blind study. Anesth Essays Res 2019;13:354-8.

14 Obayah GM, Refaie A, Aboushanab O, et al. Addition of dexmedetomidine to bupivacaine for greater palatine nerve block prolongs postoperative analgesia after cleft palate repair. Eur $J$ Anaesthesiol 2010;27:280-4.

15 Peng W, Zhang T. Dexmedetomidine decreases the emergence agitation in infant patients undergoing cleft palate repair surgery after general anesthesia. BMC Anesthesiol 2015;15:145-51.

16 Boku A, Hanamoto H, Niwa H. Effectiveness of dexmedetomidine for emergence agitation in infants undergoing palatoplasty: a randomized controlled trial. Brazil J Anesthesiol 2016;66:37-43.

17 Surana P, Parikh DA, Patkar GA, et al. A prospective randomized controlled double-blind trial to assess the effects of dexmedetomidine during cleft palate surgery. Korean $J$ Anesthesiol 2017:70:633-41.

18 Luo K, Xu J-M, Cao L, et al. Effect of dexmedetomidine combined with sufentanil on preventing emergence agitation in children receiving sevoflurane anesthesia for cleft palate repair surgery. Exp Ther Med 2017;14:1775-82.

19 Di M, Huang C, Chen F, et al. [Effect of single-dose dexmedetomidine on recovery profiles after sevoflurane anesthesia with spontaneous 
respiration in pediatric patients undergoing cleft lip and palate repair]. Zhonghua Yi Xue Za Zhi 2014;94:1466-9.

20 Xiao L, Long C, Jun F. Comparison of dexmedetomidine, ketamine and fentanyl in children undergoing cleft lip and palate surgery. Zhejiang Pract Med 2012;17:173-5.

$21 \mathrm{Xi} \mathrm{H}, \mathrm{Zu} \mathrm{H}$, Shou S. The effect of recovery quality of dexmedetomidine for cleft lip and palate repair in children. Guangdong Med J 2012;33:2490-2.

22 Yun L, Zhen L, Xu Y. Effects of intranasal dexmedetomidine for children undergoing cleft lip and palate repair surgery. Int $J$ Stomatol 2016;43:401-5.

23 Ju P, Cheng Y, Ya J. Efficacy of dexmedetomidine on recovery period in infants undergoing cleft lip and palate repair. Guangdong Med $J$ 2013;34:1439-41.

24 Jun P, Jun L, Jie L. Efficacy of dexmedetomidine on emergence agitation during recovery time in children after cleft lip and palate surgery. Zhejiang Traumatic J 2018;23:1250-1.

25 Gerresheim G, Schwemmer U. [Dexmedetomidine]. Anaesthesist 2013;62:661-74.

26 Tan D, Xia H, Sun S, et al. Effect of ancillary drugs on sevoflurane related emergence agitation in children undergoing ophthalmic surgery: a Bayesian network meta-analysis. BMC Anesthesiol 2019:19:138-49.

$27 \mathrm{Ni} \mathrm{J}$, Wei J, Yao Y, et al. Effect of dexmedetomidine on preventing postoperative agitation in children: a meta-analysis. PLoS One 2015;10:e0128450.

28 Sun L, Guo R, Sun L. Dexmedetomidine for preventing sevoflurane-related emergence agitation in children: a metaanalysis of randomized controlled trials. Acta Anaesthesiol Scand 2014;58:642-50.

29 Bellon M, Le Bot A, Michelet D, et al. Efficacy of intraoperative dexmedetomidine compared with placebo for postoperative pain management: a meta-analysis of published studies. Pain Ther 2016;5:63-80.

30 Liang X, Zhou M, Feng J-J, et al. Efficacy of dexmedetomidine on postoperative nausea and vomiting: a meta-analysis of randomized controlled trials. Int J Clin Exp Med 2015;8:12113-34.

31 Chen J-Y, Jia J-E, Liu T-J, et al. Comparison of the effects of dexmedetomidine, ketamine, and placebo on emergence agitation after strabismus surgery in children. Can $\mathrm{J}$ Anaesth 2013;60:385-92. 